\title{
SOME CONSEQUENCES OF THE SUBDUCTION OF YOUNG SLABS
}

\author{
PHILIP ENGLAND \\ Department of Geodesy and Geophysics, University of Cambridge, Madingley Rise, \\ Madingley Road, Cambridge CB3 OEZ (England) \\ and \\ RINUS WORTEL \\ Vening Meinesz Laboratorium, University of Utrecht, Budapestlaan 4, Utrecht (The Netherlands)
}

Received May 28, 1979

Revised version received January 10,1980

\begin{abstract}
The negative buoyancy force exerted by a subducting oceanic slab depends on its descent velocity, and strongly on its age. For lithosphere close to thermal equilibrium, this force dominates by a large margin the resisting forces arising from friction on the plate boundary and compositional buoyancy. This may result in oceanward migration of the trench, with associated back-arc spreading. However, the strong age dependence of this force, and of the ridge push mean that a horizontal compressive stress is required to continue subduction if changing plate geometry should bring young lithosphere to the trench. Estimates can be made of the slab age, as a function of descent velocity, at which the driving forces are no longer sufficient to overcome a given resisting force. The transition corresponding to a resisting force of $8 \times 10^{12} \mathrm{~N} / \mathrm{m}$ divides regions displaying back-arc extensional tectonics from those displaying compressional tectonics. This is in good agreement with other estimates of the forces resisting slab motion. It is suggested that an increase in the width of - or the shear stress on - the plate boundary, associated with the subduction of lithosphere to the buoyant side of this transition, can result in a compressional stress on the overriding plate which is great enough to account for cordilleran tectonics.

The proposed reduction in the one of driving forces of plate motion is still consistent with observations, being compensated by the greater relative importance of the push from the ridges.
\end{abstract}

\section{Introduction}

Elsasser [1] and McKenzie [2] remarked that the thermal contrast between a subducting oceanic slab and the surrounding upper mantle results in a force which could be large enough to drive plate motions and this view has been strengthened by the analyses of later authors (e.g. [3-5]). In the absence of chemical differentiation the cooling oceanic boundary layer must always be more dense than the subjacent upper mantle and therefore potentially unstable.

However, Oxburgh and Parmentier [6] point out that the density changes accompanying partial melting of the upper mantle to form the oceanic crust [7] may have a stabilizing effect over the first 20-40 Myr of the cooling of the oceanic lithosphere, and McKenzie [8] has shown that the initiation of subduction is a finite amplitude instability, and that more than $130 \mathrm{~km}$ of slab must be subducted before a subduction system becomes self-sustaining.

Vlaar and Wortel $[9,10]$ noted that the depth of penetration of oceanic slab into the mantle is dependent on its age, and attributed this to an age-dependent buoyancy of the lithosphere. The role of this age-dependent buoyancy in determining the tectonics of the overriding plate was recognized by these authors [9,10] and by Molnar and Atwater [11] who 
correlate cordilleran tectonics and back-arc spreading with the subduction of oceanic material respectively younger or older than about $50 \mathrm{Myr}$.

In this paper we propose a quantitative explanation of these observations, and discuss the influence which the subduction of young lithosphere may have on plate motions in general and cordilleran tectonics in particular.

\section{Forces driving and resisting subduction}

Our aim in this section is to assess the forces driving subduction of a slab as a function of its age, and to determine whether their magnitudes and age-dependence relation to the forces resisting subduction, can satisfactorily account for the observed relations between the tectonics of the overriding plate and the age of subducting oceanic lithosphere [9-11].

The principal forces driving subduction are those arising from the elevation of the mid-ocean ridge and from the density contrast between the slab and the upper mantle [8]; we shall refer to these forces as the ridge push $\left(D_{\mathrm{R}}\right)$ and the slab pull $\left(D_{\mathrm{S}}\right)$.

The forces resisting the subduction of a slab come from shearing at the plate boundary $\left(F_{\mathrm{S}}\right)$ and in the upper mantle, and possibly from compositional buoyancy of the slab $\left(F_{\mathrm{C}}\right)[6]$.

The notation used for the principal parameters in this section will be found in Table 1 .

\subsection{Resisting forces}

If the plate boundary at the subduction zone is a fault of $\operatorname{dip} \theta$ through lithosphere of thickness $S$ across which a shear stress of $\tau$ acts, the resistance to motion is $\tau S / \sin \theta$ per unit length of the boundary. (It should be noted that the dip of the plate boundary is generally much shallower than the dip of the subduction zone as a whole [53].) The shear stresses on, and the lengths of, plate boundaries are poorly determined, and it is uncertain whether these parameters bear any direct relation to the properties of the subducting slab (section 4).

TABLE 1

Assigned values and units of parameters discussed in the text.

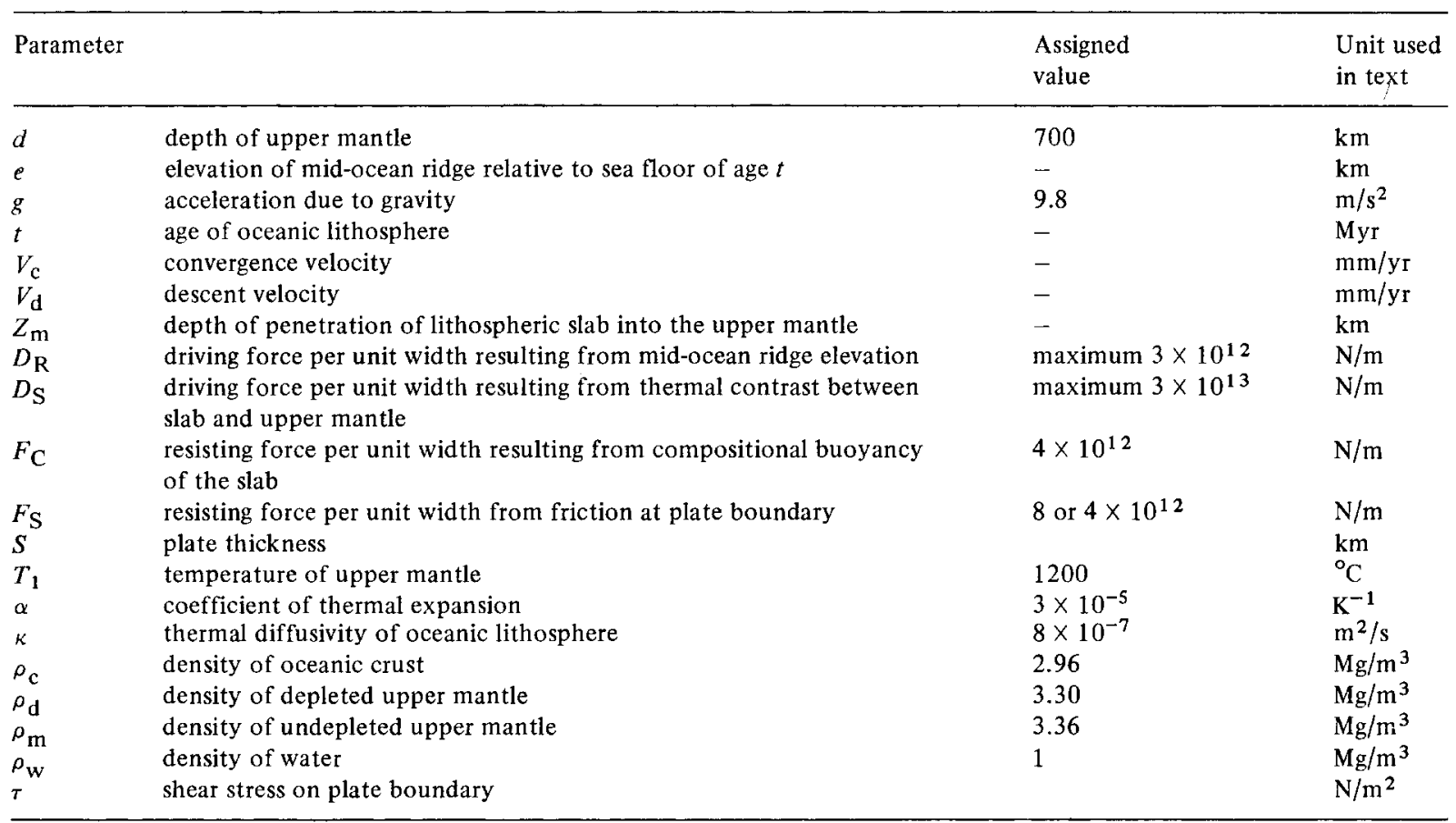


McKenzie [8] estimates $10^{\circ}$ for $\theta, 80 \mathrm{~km}$ for $S$ and 100 bars for $\tau$ to obtain a value of $4 \times 10^{12}$ $\mathrm{N} / \mathrm{m}$ for $F_{\mathrm{S}}$, the resisting force arising from shear stresses at the plate boundary. An independent assessment may be made by considering the total amount of heat which can be converted into mechanical work by convection in the mantle; in this way McKenzie and Jarvis [54, case C] estimate the average resisting force at convergent plate boundaries to be $8 \times 10^{12} \mathrm{~N} / \mathrm{m}$.

The compositional buoyancy of the oceanic lithosphere derives from its basaltic crust and depleted uppermost mantle [6]; each of these is less dense than the subjacent upper mantle would be at equivalent temperature and pressure, thus the cold descending slab may be more buoyant than is calculated by assuming it to be identical to the upper mantle (e.g. in equation (2), below).

It is probable that the compositional buoyancy in the oceanic lithosphere is removed by the conversion of basaltic crust to eclogite at less than $100 \mathrm{~km} \mathrm{[6];}$ using Oxburgh and Parmentier's crust and depleted upper mantle thicknesses $(8+21 \mathrm{~km})$ and densities (Table 1) gives a value for the resulting buoyancy force of $4 \times 10^{12} \mathrm{~N} / \mathrm{m}$ which would be reduced if crust and depleted zone were to decouple above this level. If the crust alone decouples the buoyancy of the depleted upper mantle amounts to $1.25 \times 10^{12}$ $\mathrm{N} / \mathrm{m}$ for each $100 \mathrm{~km}$ vertical extent of the slab - or a maximum of about $9 \times 10^{12} \mathrm{~N} / \mathrm{m}$ for a slab which penetrates to the base of the upper mantle.

\subsection{Driving forces}

The principal driving forces of subduction are the push from the mid-ocean ridge and the pull by the cold, descending slab.

The first is a function of the elevation, $e$, of the mid-oceanic ridge relative to the ocean floor and of the thickness, $S$, of the lithosphere [5, equation 25]:

$D_{\mathrm{R}}=g e\left(\rho_{\mathrm{m}}-\rho_{\mathrm{w}}\right)\left(\frac{S}{3}+\frac{e}{2}\right)$

The driving force resulting from the temperature contrast between slab and surrounding mantle is also given by Richter and McKenzie [5, equation 27]:

$D_{\mathrm{S}}=\frac{4 g \alpha \rho_{\mathrm{m}} T_{1} S^{3} V_{\mathrm{c}}\left[1-\exp \left(-\pi^{2} d \kappa / V_{\mathrm{c}} S^{2}\right)\right]}{\kappa \pi^{4}}$ (for notation see Table 1.) In the derivation of this equation the slab is assumed to be vertical; in comparing observations from different subduction zones, the descent velocity, $V_{\mathrm{d}}$, is calculated from the dip of the slab and the convergence velocity. The thickness of oceanic lithosphere as a function of age is not easy to determine; it seems likely that it obeys a square-root-of-age law, like the heat flow and the bathymetry, until an age of $70 \mathrm{Myr}$ when these relations break down [14], but its behaviour at greater ages than this may well be determined by the dynamics of small-scale convection in the upper mantle [13].

We make the assumption that the thickness has the same time-dependence as the other temperaturedependent observables of the oceanic lithosphere and we relate it to the better constrained of these, the bathymetry.

Parsons and Sclater [14] show that the elevation, $e$, of mid-ocean ridge above ocean floor of age $t \mathrm{Myr}$ conforms well to the relations:

$$
\begin{array}{ll}
e=0.35 \sqrt{t} \mathrm{~km} & t \leqslant 70 \mathrm{Myr} \\
e=[3.90-3.2 \exp (-t / 62.8)] \mathrm{km} & t>70 \mathrm{Myr}
\end{array}
$$

Parsons and McKenzie [13] infer the age dependence of oceanic mechanical boundary layer thickness, $S$, (which they define by the isotherm $975^{\circ} \mathrm{C}$ ) to be:

$$
S=8.2 \sqrt{t} \mathrm{~km} \quad t<70 \mathrm{Myr}
$$

with $t$ in Myr and the value of thermal diffusivity given in Table 1. They make no estimate of the thickness of the boundary layer for ages greater than 70 $\mathrm{Myr}$, except to predict an equilibrium value of $91 \mathrm{~km}$. We adopt these estimates as appropriate indications of slab thickness.

The equilibrium values and values at ages less than $70 \mathrm{Myr}$ for bathymetry and boundary layer thickness both give:

$S(t)=23.4 e(t)$

and this relation is used to give $S$ for all ages of oceanic lithosphere. This assumption permits the calculation of driving forces as a function of the age of subducting slab, subject to the uncertainties discussed below.

\subsection{Uncertainties}

In evaluating the balance of forces as a function of the age of subducting slab, we will be concerned with 
finding the difference between two large numbers; this can be a misleading pastime, and it is as well to be aware of the magnitude of the uncertainties in the following calculations.

The largest uncertainty comes from the possible elevation of the olivine-spinel phase change in the descending slab $[16,17]$; this effect would be most pronounced for rapidly descending slabs, and could be over $100 \mathrm{~km}$, contributing $1.5 \times 10^{13} \mathrm{~N} / \mathrm{m}$ to the driving force. This is offset by the consideration that the descending slabs may not be able to support the deviatoric stresses such a force would imply [5], and the observations that parts of some slabs seem to be detached [15].

An increase of $5 \times 10^{12} \mathrm{~N} / \mathrm{m}$ in the slab pull is achieved by assuming an equilibrium thickness of 125 $\mathrm{km}$, and proportionately greater thickness at younger ages, rather than the values in equations (3) to (5).

Richter and McKenzie [5] consider that an average shear stress of $10^{7} \mathrm{~N} / \mathrm{m}^{2}$ may act on the lower portions of the slabs which descend most rapidly through the deep upper mantle. We are mainly interested in the forces involved in the subduction of young lithosphere which generally does not penetrate below 350 $\mathrm{km}[9,10]$, but it must be remembered that ignoring the shearing resistance could lead to an error of around $4 \times 10^{12} \mathrm{~N} / \mathrm{m}$ in $F_{\mathrm{S}}$.

\subsection{The force balance}

McKenzie [8] considers the problem of initiation of subduction, when it is most favourable to subduct old lithosphere with a near-equilibrium thermal structure. We consider the balance of forces when the age of lithosphere approaching a trench is no longer great enough for it to be considered as being in thermal equilibrium. In this case, the negative buoyancy of the subducted slab may no longer be great enough to overcome the resistive forces and an extra compressive stress would be required to maintain the subduction; this could still be energetically preferable to starting subduction elsewhere because of the large amount of work required to initiate a new subduction zone [8].

It is clear from the discussion above that the uncertainties in the resisting forces are large and that there is no simple relation between them and the age of the slab comparable to those existing for the slab pull and ridge push. In the next section we assume initially that the resisting forces are independent of slab parameters and attempt to determine their magnitude using observations from slabs of known ages and descent velocities.

\section{Application}

As an example of the balance of forces under these simplifying assumptions, we take a case in which the total force resisting subduction is $12 \times 10^{12} \mathrm{~N} / \mathrm{m}$. This might correspond, for example, to $8 \times 10^{12} \mathrm{~N} / \mathrm{m}$ for $F_{\mathrm{S}}$ and $4 \times 10^{12} \mathrm{~N} / \mathrm{m}$ for $F_{\mathrm{C}}$ : that is, to a shear stress of 140 bars on a plate boundary dipping at $10^{\circ}$ through a plate $100 \mathrm{~km}$ thick, combined with the compositional buoyancy of $100 \mathrm{~km}$ vertical extent of differentiated lithosphere.

The net force driving the subduction of a slab would then be the sum of $D_{\mathrm{S}}$ and $D_{\mathrm{R}}$ (equations (1)

\section{TABLE 2}

Balance of forces for slabs of different ages and subduction velocities: net force per unit width, $F_{\mathrm{T}}$, favouring subduction is given by $F_{\mathrm{T}}=D_{\mathrm{S}}+D_{\mathrm{R}}-F_{\mathrm{S}}-F_{\mathrm{C}} \cdot F_{\mathrm{S}}$ is fixed at $8 \times 10^{12}$ $\mathrm{N} / \mathrm{m}$ and $F_{\mathrm{C}}$ at $4 \times 10^{12} \mathrm{~N} / \mathrm{m} ; D_{\mathrm{S}}$ and $D_{\mathrm{R}}$ are calculated from equations (1) to (5) with the parametral values given in Table 1. Negative $F_{\mathrm{T}}$ indicates that resisting forces are greater than driving forces. Note that in this calculation $\theta$ is $90^{\circ}$, while in Fig. 1 it is taken to be $45^{\circ}$

\begin{tabular}{|c|c|c|c|}
\hline \multicolumn{2}{|c|}{$V_{\mathrm{d}}=30 \mathrm{~mm} / \mathrm{yr}$} & \multicolumn{2}{|c|}{$V_{\mathrm{d}}=60 \mathrm{~mm} / \mathrm{yr}$} \\
\hline $\begin{array}{l}\text { age } \\
(\text { Myr) }\end{array}$ & $\begin{array}{l}F_{\mathrm{T}} \\
\left(10^{12} \mathrm{~N} / \mathrm{m}\right)\end{array}$ & $\begin{array}{l}\text { age } \\
\text { (Myr) }\end{array}$ & $\begin{array}{l}F_{\mathrm{T}} \\
\left(10^{12} \mathrm{~N} / \mathrm{m}\right)\end{array}$ \\
\hline 1 & -12.0 & 1 & -12.0 \\
\hline 3 & -11.8 & 3 & -11.6 \\
\hline 10 & -10.8 & 10 & -9.8 \\
\hline 20 & -8.8 & 20 & -6.8 \\
\hline 30 & -6.6 & 30 & -3.9 \\
\hline 40 & -4.4 & 40 & -1.4 \\
\hline 50 & -2.2 & 50 & 0.9 \\
\hline 60 & 0.2 & 60 & 3.1 \\
\hline 70 & 1.1 & 70 & 4.3 \\
\hline 80 & 2.5 & 80 & 5.7 \\
\hline 90 & 3.7 & 90 & 6.9 \\
\hline 100 & 4.7 & 100 & 7.9 \\
\hline 110 & 5.6 & 110 & 8.8 \\
\hline 120 & 6.3 & 120 & 9.5 \\
\hline 130 & 7.0 & 130 & 10.1 \\
\hline
\end{tabular}


to (5)) minus this force; Table 2 shows the balance of these forces as a function of the age of the slab for two values of descent velocity. The age at which the driving forces overcome the resisting forces depends on the velocity with which the slab descends into the mantle, $V_{\mathrm{d}}$; this influences the depth that it reaches before it loses its thermal identity [2]. The maximum penetration depth of $700 \mathrm{~km}$ imposes a limit on $D_{\mathrm{S}}$ [5].

The significance of the force balances shown in Table 2 may be understood in the following terms. We assume that the initiation of a subduction zone generally involves the depression of old lithosphere, close to thermal equilibrium, into the mantle.

Although this material is denser than the surrounding mantle, a compressive stress of about 800 bars is required to initiate this movement, and it is not until the slab has penetrated to a depth of $130 \mathrm{~km}$ that the driving forces are large enough to overcome the resistive forces [8].

Note that the resistive force arising from bending the lithosphere [8] does not apply in this case (because the deformation is assumed to be elastic and therefore reversible) except in so far as some portion of the deformation may be ductile.

Once established, such a subduction zone is selfsustaining and will reach a steady state with the slab attaining a penetration depth that, except for slabs with descent velocities less than about $30 \mathrm{~mm} / \mathrm{yr}$, is the base of the upper mantle. Under these circumstances, the driving forces may outweigh the resistive forces by about $10^{13} \mathrm{~N} / \mathrm{m}$ (Table 2). These conditions would permit, and may be the cause of, the oceanwards migration of the subduction zone (see section 4). Many present-day subduction zones where these conditions are obtained have a marginal basin behind them in which active or late Tertiary spreading is recognized [11].

A change in the geometry of plate movement may result in the subduction of younger lithosphere at the trench and if this change continues, the negative buoyancy of the slab may no longer be sufficient to overcome the resistive forces; for the examples shown in Table 2 this transition takes place when the average age of the subducting slab is $70-40 \mathrm{Myr}$.

For the subduction of still younger lithosphere to occur, a horizontal compressive force must exist in addition to the driving forces discussed above, in order

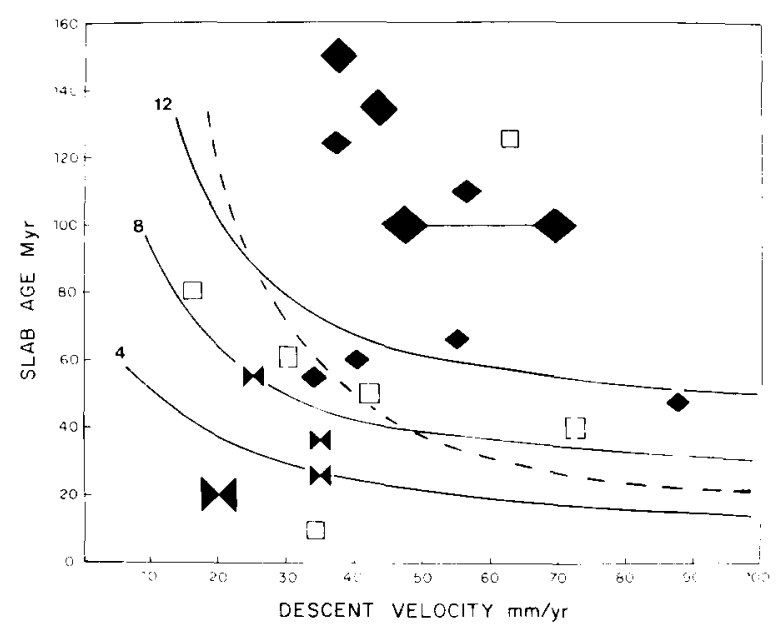

Fig. 1. Solid line shows the age of slab at which the driving forces on it are equal to the resisting forces, as a function of the vertical velocity of the slab through the upper mantle (equations (1) to (5)). The lines show the position of this transition for resisting forces of 4,8 and $12 \times 10^{12} \mathrm{~N} / \mathrm{m}$. Present-day subduction zones are plotted according to the descent velocity of the slab in the mantle (inferred from con vergence velocity and $s l a b$ dip) and $i$ ts average age; in general the latter is close to, but not identical with, the age of oceal floor near the trench. The diamonds represent slabs behind which spreading occurs and the double-arrowheads, slabs behind which compressional or cordilleran [11] tectonics occur; open squares indicate slabs behind which there is no clear evidence of compression or tension. Further details are given in section 3 and Table 3 .

to overcome the resistance to subduction. For the subduction of lithosphere less than $20 \mathrm{Myr}$ old this force needs to be around $10^{13} \mathrm{~N} / \mathrm{m}$, in the example of Table 2, implying a compressive stress of $1 \mathrm{kbar}$ or more if the mechanical boundary layer is $90 \mathrm{~km}$ thick.

The heavy lines in Fig. 1 show the age of this transition as a function of descent velocity (equations (1) to (5)) for three different values of the resisting forces $-4,8$ and $12 \times 10^{12} \mathrm{~N} / \mathrm{m}$ - and a slab dip of $45^{\circ}$.

Information on regional stress regimes behind subduction zones is limited and of variable value for the present application. However, we have summarized this information, with its sources, in Table 3 for subduction zones where a descent velocity and a slab age can satisfactorily be assigned. The individual zones are plotted according to these parameters in Fig. 1. Zones 
TABLE 3

Subduction zones: parameters and tectonics

\begin{tabular}{|c|c|c|c|c|c|c|}
\hline $\begin{array}{l}\text { Subduction } \\
\text { zone }\end{array}$ & $\begin{array}{l}\text { Age of sub- } \\
\text { ducted oceanic } \\
\text { lithosphere } \\
\text { (Myr) }\end{array}$ & $\begin{array}{l}\text { Convergence } \\
\text { rate, normal } \\
\text { to plate } \\
\text { boundary } b \\
(\mathrm{~mm} / \mathrm{yr})\end{array}$ & $\begin{array}{l}\text { Dip angle } \\
\text { of } \\
\text { Benioff } \\
\text { zone }^{c}\end{array}$ & $\begin{array}{l}\text { Descent } \\
\text { velocity } \\
(\mathrm{mm} / \mathrm{yr})\end{array}$ & $\begin{array}{l}\text { Predicted } \\
\text { tectonics }\end{array}$ & Tectonics \\
\hline $\begin{array}{l}\text { Kurile } \\
\text { Northern }\end{array}$ & 110 & 80 & 45 & 56 & + & Late Tertiary spreading [18] \\
\hline Honshu & 125 & 82 & 27 & 37 & + & Late Tertiary spreading [18] \\
\hline Southwestern & & & & & & \\
\hline Honshu & 25 & 35 & $-f$ & $<35$ & - & compression (references in [47]) \\
\hline Izu-Bonin & 135 & 61 & 45 & 43 & + & active spreading [38] \\
\hline Mariana & 150 & 38 & 90 & 38 & + & active spreading [38] \\
\hline Ryukyu & 60 & 56 & 45 & 40 & + & active spreading [39] \\
\hline \multicolumn{7}{|l|}{ Tonga/Kermadec } \\
\hline $\left.\begin{array}{l}\left(20^{\circ} \mathrm{S}\right) \\
\left(34^{\circ} \mathrm{S}\right)\end{array}\right\}$ & $\sim 100$ & $\begin{array}{l}90 \\
61\end{array}$ & & $\begin{array}{l}69 \\
47\end{array}$ & $\begin{array}{l}+ \\
+\end{array}$ & active spreading [38] \\
\hline New Hebrides & $45-50$ & $>100$ & 60 & $>87$ & + & minor extensional tectonics \\
\hline Java & 125 & 69 & 65 & 63 & + & simple e \\
\hline Sumatra & $50-70$ & 61 & 30 & 30 & 0 & $\begin{array}{l}\text { simple }{ }^{\mathrm{e}} \text { (possibly N-S compres- } \\
\text { sion [49]) }\end{array}$ \\
\hline \multicolumn{7}{|l|}{$\begin{array}{c}\text { Southern Peru- } \\
\text { Northern }\end{array}$} \\
\hline Chile & $65-70^{g}$ & 110 & 30 & 55 & + & extensional tectonics $[34]$ \\
\hline \multicolumn{7}{|l|}{ Northern-central } \\
\hline Peru & $50-55^{\mathrm{g}}$ & 100 & 15 & 26 & - & compression $[34,35]$ \\
\hline Central America & 40 & 94 & 50 & 72 & + & simple $[50]$ \\
\hline Mexico & $\sim 20$ & 66 & $15-20$ & 20 & - & compressional tectonics [51] \\
\hline Lesser Antilles & $\sim 80$ & 20 & 55 & 16 & 0 & simple $^{\mathrm{e}}[36]$ \\
\hline Cascades & $\sim 10$ & 35 & $-\mathbf{f}$ & $<35$ & - & simple $^{\mathrm{e}}$ \\
\hline Alaska & $35-40$ & 58 & $35-40$ & 35 & - & compression [37] \\
\hline \multicolumn{7}{|l|}{ Aleutians } \\
\hline$\left(180^{\circ} \mathrm{W}\right)$ & 55 & 48 & 45 & 34 & 0 & inactive basin, high heat flow [38] \\
\hline$\left(160^{\circ} \mathrm{W}\right)$ & 50 & 67 & $35-40$ & 41 & 0 & $\begin{array}{l}\text { inactive basin, normal heat flow } \\
{[38]}\end{array}$ \\
\hline
\end{tabular}

a From references 23, 24, 25, 46, 10 .

b From references 26, 27, 31, 32, 48 .

c From references 15, 28, 29, 30.

d Large (small) addition signs indicate that driving forces outweigh resistive forces by more (less) than $5 \times 10^{12} \mathrm{~N} / \mathrm{m}$, large (small) subtraction signs, that compressive force of more (less) than $5 \times 10^{12} \mathrm{~N} / \mathrm{m}$ is required to maintain subduction; zeros indicate regimes with net driving force between $\pm 10^{12} \mathrm{~N} / \mathrm{m}$.

e Without dominance of compressional or tensional tectonics [11].

f No clear Benioff zone.

g From reference [10].

behind which there is evidence of compressional tectonics are represented by double arrowheads and those accompanied by extension, by diamonds. The larger symbols indicate zones with the clearer evidence of present-day compressional or tensional regimes.

The open squares represent zones without dominance of compressional or tensional tectonics ("simple" of
Molnar and Atwater [11]).

The most striking feature of Fig. 1 is that the line corresponding to a net resisting force of $8 \times 10^{12}$ $\mathrm{N} / \mathrm{m}$ divides the regions showing back-arc extension from those showing compression. Furthermore, with two discrepancies - Java and the Cascades - the regions with no clear evidence of compression or 
tension lie close to this line.

This is suggestive of the idea that the average force resisting slab subduction is around $8 \times 10^{12} \mathrm{~N} / \mathrm{m}$ and that those slabs with insufficient slab pull and ridge push to overcome this resistance must be subjected to an additional compressive stress for subduction to proceed.

This estimate of the resisting forces is certainly in good agreement with previous ones (e.g. $[5,8]$ ) but there are several caveats about such a simplified view. First, in reality we do not expect the resisting forces to be independent of slab parameters (section 4) so the value of $8 \times 10^{12} \mathrm{~N} / \mathrm{m}$ is only an estimate of the resistance to subduction close to the transition between compressional and extensional regimes.

Secondly, the classification of back-arc regimes as extensional or compressional ought ideally to be on the basis of focal mechanisms throughout the overriding plate. Unfortunately, we have often had to rely on less direct evidence (Table 3 ) and these indications may admit of more than one interpretation. We have adopted Molnar and Atwater's [11] nomenclature for regions showing dominance of neither tension nor compression, while acknowledging that "simple" is not the word most likely to occur to the geologists who work there, and two other examples of the uncertainties in characterising tectonic regime from these indirect data follow.

First, regions in which subduction of young lithosphere has recently stopped may exhibit extensional tectonics even if they were under compression when subduction was active. This behaviour is perhaps the case in the Great Basin where the Middle Miocene to present extensional phase with associated basaltic volcanism (e.g. $[40,41]$ ) was subsequent, and perhaps consequent, upon the annihilation of a Mid-Cenozoic subduction zone along this portion of the west coast $[41,42]$. The subduction of the very young oceanic lithosphere in the late stages presumably required large compressive stress (Table 2) which was released when subduction stopped. Tensional regimes could result from the reheating of subducted lithosphere, stresses involved in reorientating plate motions [42] or diapirism [43], but it would be misleading to classify these regimes with the back-arc spreading associated with subduction of old lithosphere.

Secondly, surface manifestations of tensional stress may not reflect the average stress throughout the lithosphere; it is easy to imagine near-surface tension associated with intrusions in a regime that is fundamentally compressive. It is desirable, therefore, to determine the state of stress from focal mechanism data distributed throughout the lithosphere, where possible, in these terrains. These considerations have been applied when considering the data for the necessarily short summary of Table 3 ; as an example a region where the tectonics undergo the transition from tension to compression is briefly described here.

The Andes in northern-central Peru (approximately from $5^{\circ}$ to $15^{\circ} \mathrm{S}$ ) are in east-west compression, as shown by field data [34]; the Benioff zone dip is quite shallow here, and there is considerable seismic activity in the overriding plate with focal mechanisms indicating compression $[35,44]$. From about $15^{\circ}$ to $27^{\circ} \mathrm{S}$ the stress seems to be predominantly tensional [34], the Benioff zone dips more steeply and there is no significant seismic activity in the upper plate [29]. South of this, the seismicity closely resembles that between $5^{\circ}$ and $15^{\circ} \mathrm{S}[29]$, although, because focal mechanisms are lacking, it is not included in Table 3. Wortel and Vlaar [10] noted that changes in age of subducted slab associated with these zones and commented on their relation to slab dip, seismicity, and volcanism in the region. Equations (1) to (5) predict compression in the region $5-15^{\circ} \mathrm{S}$ and tension from $15^{\circ}$ to $27^{\circ} \mathrm{S}$ (northern-central Peru; southern Peru-northern Chile, Table 3).

Finally, the transition between tensional and compressional regimes may result from a completely different buoyancy requirement: the dashed line in Fig. 1 illustrates the descent velocity as a function of age required for a slab to penetrate to a depth of $300 \mathrm{~km}$ with at least some portion of it below $800^{\circ} \mathrm{C}$. This might correspond to the conditions required to elevate the olivine-spinel transition within the slab enough to provide the driving force necessary to overcome resistance to subduction (section 2).

There is, as yet, little evidence that this mechanism occurs; nor is it certain that the slabs are capable of sustaining the shear stresses which would result from it if it did occur. Much of the discussion of the next two sections is unaffected by the details of the transition between tensional and compressional regimes and we prefer to continue the arguments in terms of the better-constrained driving forces outlined in section 2. 


\section{Tensional and compressional regimes}

In the previous section we estimated the magnitude of the forces resisting the subduction of slabs in the vicinity of the transition from tensional to compressional tectonics in the overriding plate. This value of around $8 \times 10^{12} \mathrm{~N} / \mathrm{m}$ may come entirely from resistance at the plate boundary or may result in part from the compositional buoyancy of the slab. For the sake of argument we assume that half of this force arises from the compositional buoyancy $(100 \mathrm{~km}$ of crust and depleted upper mantle, or $300 \mathrm{~km}$ of depleted upper mantle alone, section 2) and the rest from friction on the plate boundary.

Under these conditions, a compressional force of $4 \times 10^{12} \mathrm{~N} / \mathrm{m}$ acts on the overriding plate owing to the shearing at the plate boundary; this force, which is equivalent to a stress of 400 bars over a $100-\mathrm{km}$ plate, is of similar magnitude to the force arising from the elevation differences between continents and ocean basins, thus it is arguable that it may be balanced without appreciable deformation of the overriding plate. It is in considering the compressional regimes behind subduction zones containing young slabs, or the tensional regimes behind old slabs, that the problem becomes more complex.

We have suggested above that the negative buoyancy of old slabs may exceed the forces resisting subduction by $10^{13} \mathrm{~N} / \mathrm{m}$, or more. Under these conditions there is a component (arising from the large negative buoyancy) of the net force on the slab which acts oceanwards, and we should expect the trench to migrate oceanwards - albeit slowly because this involves moving a tabular slab through the asthenosphere in a direction perpendicular to its long axis. Alternative hypotheses for back-arc spreading, driven by ascent of asthenosphere [8] or parts of the descending lithosphere [6] or by secondary circulation behind the subduction zone [2] cannot be excluded. If one of these were the case the transition to a compressional regime on subduction of young lithosphere would merely suppress a tendency to spreading common to all subduction zones. However, the approach we have adopted tends to favour the view that extensional back-arc tectonics are controlled by the balance of forces on the subducting slab (e.g. $[11,57])$ rather than by the mechanisms above or by the relative motions of overriding and subducting plates (e.g. $[55,58]$ ).
The origin of cordilleran tectonics can also be explained in terms of the balance of forces on the slabs. When the negative buoyancy force from the subducted lithosphere is no longer sufficient to overcome the resisting forces, an additional compressive force is required. This force is presumably available from stable subduction on other parts of the plate and from the ridge push ([8], and section 5, this paper). In the absence of a large negative buoyancy force there is now a net force acting landwards on the oceanic lithosphere at the trench. However, we are not justified in assuming that this alone accounts for cordilleran tectonics because, unless there is a change in the coupling between the plates, the overriding plate will experience no greater compressive stress than in the cases discussed above.

We suggest that the absence of a large negative buoyancy force on the slab may result in a generally shallower dip of the plate boundary in zones where young slab is being subducted. There are obviously other factors which control slab geometry (not least the loading by accretionary prisms [53]) but this suggestion is supported by the observations of Kelleher et al. [58]: Many of the regions with broad interface zones between underthrust and overthrust lithosphere are also regions having slabs with low negative buoyancy (Table 3). This view point is also supported by the observation that generally the regions of most intense cordilleran activity are associated with shallowly dipping slabs.

If the width of the plate boundary is doubled while the shear stress remains constant, the compressive stress on the overriding plate would rise to 800 bars, which is probably large enough to account for considerable crustal shortening (cf. the compressional stresses discussed by Tapponier and Molnar [45] for the Himalayas).

We emphasise that this is a tentative explanation for the origin of the forces driving cordilleran tectonics; doubtless further complexities are yet to be discovered.

Changes in Benioff zone geometry have frequently been invoked as causes of compressive orogeny in cordilleran zones; the important change is usually taken to be a reduction in dip associated with an increase in convergence rate. We have suggested that shallow dips may be associated with the subduction of young lithosphere and hence with compressive 
regimes (see also Vlaar and Wortel $[9,10]$ ) but this is by no means always the case, and large dips may also be associated with compressional regimes. It may be that the subduction of more buoyant slabs is associated with generally higher shear stress at the plate boundary (e.g. [56]) and we prefer simply to emphasise that the development of compressional tectonics in cordilleran terrains is expected to be consequent on changes in the subduction process which cause it to cross the transition in Fig. 1 from aboveright to below-left. This can be brought about either by a reduction in age, and therefore negative buoyancy of the subducting slab, or by a decrease in its descent velocity; the latter could result from the former or from a decrease in convergence rate.

This process will not necessarily be accompanied by an increase in the total resisting forces: the compositional buoyancy force may be smaller in the young slabs which do not penetrate far into the upper mantle than it is in older slabs, and this may offset to some extent the increased resistance at the plate boundary. There is no reason to expect exact balance however, and the implications for plate motions of an increased resisting force at cordilleran boundaries are discussed in section 5 .

\section{Plate motions}

The proposed variation with age of the buoyancy of subducted oceanic lithosphere predicts that, in zones where young oceanic lithosphere is consumed, the driving forces arising from the thermal structure of the plates $\left(D_{\mathrm{R}}+D_{\mathrm{S}}\right)$ may not be large enough to overcome the resistive forces. The analyses of several authors [3-5] suggest that the negative buoyancy of subducting slabs, and possibly the ridge push, are the major forces responsible for plate motions. Our hypothesis does not provide alternative driving forces, so it should not predict magnitudes for the accepted forces that conflict with the observational constraints. One constraint is that the decrease in driving force resulting from the subduction of young rather than old lithosphere must not make the global sum of these forces small compared with the likely resistive forces. Secondly, the balance of forces on individual plates ought to be in agreement with their inferred absolute velocities.
We do not propose a detailed examination of the driving forces of plate motion, but make below two simple calculations of the influence that age-dependent buoyancy of the slab ought to have on the force balances. We assign a driving force to each section of slab according to equations (2) to (5); ages and descent velocities are taken from Pitman et al. [23], Hilde et al. [44] and the sources of Table 3. Summing this force over the $36,000 \mathrm{~km}$ of slab gives a total driving force of $4 \times 10^{20} \mathrm{~N}$ - compared with $5 \times$ $10^{20} \mathrm{~N}$ available if all the slabs had the driving force appropriate to their descent velocities but with equilibrium thermal structure [5, fig. 9]. Clearly the change in the global sum of driving forces when the age-dependent buoyancy of slabs is considered is small, but note that most of the slab pull acts on only two plates (Table 4).

We have suggested that there is an average force of $8 \times 10^{12} \mathrm{~N} / \mathrm{m}$ resisting slab motion, which leaves a net driving force from the slabs of $10^{20} \mathrm{~N}$. An additional force of $1.2 \times 10^{20} \mathrm{~N}$ comes from the ridges $\left(60,000 \mathrm{~km}\right.$ at $2 \times 10^{12} \mathrm{~N} / \mathrm{m}$ : equation (1) and (5)), giving a total of $2.2 \times 10^{20} \mathrm{~N}$ to overcome resistance to motion at plate bases, cordilleran boundaries, etc.

It is suggested in section 4 that an additional resisting force - above the estimated average of $8 \times$ $10^{12} \mathrm{~N} / \mathrm{m}$ - is associated with the cordilleran activity accompanying the subduction of young slabs. The combined length of the Himalayan, Rockies and Andes systems is $23,000 \mathrm{~km}$ with an average elevation of $3 \mathrm{~km}$. McKenzie estimates a force of $7 \times 10^{12} \mathrm{~N} / \mathrm{m}$ if none of the stress is supported elastically in such a region [8]; this implies an additional $1.6 \times 10^{20} \mathrm{~N}$ at most which must be overcome by the driving forces.

As this is certainly an over-estimate there is no shortfall in the global driving force balance.

We employ a similarly simplified calculation in assessing the force balance on the individual plates, considering first the balance of forces when it is assumed that all the resistance to motion arises at the plate boundaries, and further that the resistance to motion at divergent and transform boundaries is negligible with respect to that experienced at convergent margins. This resistance ought to be proportional to the convergence rate at the plate boundary, and we take as a measure of the latter, the absolute plate velocity with respect to the mesosphere [3]. This is a fair approximation for the fast- 
TABLE 4

Force balances on individual plates

\begin{tabular}{|c|c|c|c|c|c|c|c|c|c|}
\hline Plate $^{a}$ & $\begin{array}{l}\text { (Total) }{ }^{a} \text { a } \\
\text { effective s } \\
\text { length b } \\
(\mathrm{km})\end{array}$ & $\begin{array}{l}\text { and } \\
\text { slab }\end{array}$ & $\begin{array}{l}\text { Effective } \\
\text { ridge } \\
\text { length } \mathrm{c} \\
(\mathrm{km})\end{array}$ & $\begin{array}{l}\text { (Total } \\
\text { effecti } \\
\text { pull } \\
\left(10^{18}\right.\end{array}$ & $\begin{array}{l}\text { e and } \\
\text { ive slab } \\
\text { N) }\end{array}$ & $\begin{array}{l}\text { Effective } \\
\text { ridge } \\
\text { push } \\
\left(10^{18} \mathrm{~N}\right)\end{array}$ & $\begin{array}{l}\text { Convergent } \\
\text { plate } \\
\text { boundaries } \mathrm{c} \\
(\mathrm{km})\end{array}$ & $\begin{array}{l}\text { Plate } \\
\text { area } \\
\text { c }\end{array}$ & $\begin{array}{l}\text { Absolute } \\
\text { plate } \\
\text { velocity } \\
(\mathrm{mm} / \mathrm{yr})\end{array}$ \\
\hline PAC & $(12,400)$ & 11,400 & 11,900 & (162) & 63 & 24 & 16,700 & 108 & 80 \\
\hline IND & $(9100)$ & 6500 & 10,800 & (107) & 35 & 22 & 17,100 & 60 & 61 \\
\hline NAZ & $(5300)$ & 1700 & 5400 & (42) & 0 & 11 & 6300 & 15 & 76 \\
\hline $\mathrm{COC}$ & $(2500)$ & 1700 & 2900 & (19) & -1 & 6 & 3200 & 2.9 & 86 \\
\hline PHI & (4200) & 4200 & - & (40) & 6 & - & 7100 & 5.4 & 64 \\
\hline NAM & (1200) & - & 8600 & (10) & - & 17 & 10,200 & 60 & 11 \\
\hline ARA & - & - & 2700 & - & - & 5 & 3200 & 4.9 & 42 \\
\hline SAM & $(500)$ & - & 7100 & (4) & - & 14 & 9300 & 41 & 13 \\
\hline AFR & $(1000)$ & - & 5800 & (8) & - & 12 & 6900 & 79 & 21 \\
\hline EUR & - & - & 3500 & - & - & 7 & 27,500 & 69 & 7 \\
\hline ANT & - & - & 1700 & - & - & 3 & 1700 & 59 & 17 \\
\hline CAR & - & - & - & - & - & - & 4400 & 3.8 & $6^{\mathrm{d}}$ \\
\hline
\end{tabular}

a $\quad$ PAC $=$ Pacific $;$ IND $=$ Indian $;$ NAZ $=$ Nazca $;$ COC $=$ Cocos $;$ PHI $=$ Philippines $;$ NAM $=$ North America $;$ ARA $=$ Arabia $;$ SAM $=$ South America; AFR = Africa $; \mathrm{EUR}=$ Europe ANT = Antarctica $; \mathrm{CAR}=$ Caribbean $[3]$.

b Effective slabs are: PAC Kuriles-Japan-Izu-Mariana, Tonga; IND Java, New Hebrides; NAZ southern Peru - northern Chile; PHI Philippines-Ryukyu.

c From Forsy th and Uyeda [3] unless otherwise indicated.

d From Jordan [32].

e See text.

moving plates with a high proportion of slabs on their boundaries, as in general they move towards their slabs with an absolute velocity close to the convergence velocities, and in view of the simplicity of the calculation, no better approximation is warranted. We should expect this assumption to underestimate the resisting forces in the case of the slower moving plates.

Table 4 gives the force balance on the twelve plates of Forsyth and Uyeda [3]: effective slabs are those portions where the negative buoyancy forces are greater than $8 \times 10^{12} \mathrm{~N} / \mathrm{m}$; total slab pull is calculated from equations (2) to (5) for each section of the slab and effective slab pull is the total less $8 \times$ $10^{12} \mathrm{~N} / \mathrm{m}$ of slab. The ridge push for each plate is calculated from the effective ridge length [3] and a driving force of $2 \times 10^{12} \mathrm{~N} / \mathrm{m}$ of ridge length for the plate.

Fig. 2A plots the ratio of total driving force (total slab pull + ridge push) to convergent boundary length against absolute velocity over the mesosphere, for the twelve plates. The five fastest-moving plates group together in a region of the plot with high ratio of driving force to plate boundary length, indeed they lie close to a line of $8 \times 10^{12} \mathrm{~N} / \mathrm{m}$ which is our preferred estimate of the resisting force at the plate boundaries.
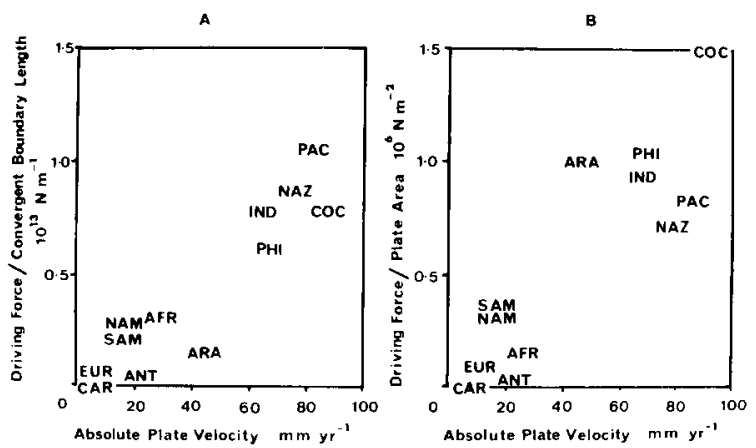

Fig. 2. A. The ratio of driving force to convergent plate boundary length plotted against absolute plate velocity for the twelve plates of Forsyth and Uyeda [3]. Data from Table 4. B. As Fig. 2A except that the driving dorce is divided by plate area. 
If account is taken of the forces at the plate boundary, the major remaining resistance to motion arises at the base of the plates. In Fig. 2B the driving force for each plate calculated from the effective slab pull and the ridge push is divided by the plate area and plotted against plate velocity. Again, the fastestmoving plates have the highest ratios of driving force to resisting boundary and the slowest ones have the lowest ratios. It is particularly encouraging that the Nazca and Cocos plates plot with the other fast-moving plates, because the model we have proposed in the previous sections has removed all of the slab pull from these plates (Table 4) and they are now regarded as being driven by their relatively high proportions of effective ridge. Even in the larger fastmoving plates, the ridge push is an important fraction of the driving force (compare effective ridge push and effective slab pull for PAC and IND in Table 4).

The resisting forces at convergent plate boundaries are predicted to be in the region of $4-8 X$ $10^{12} \mathrm{~N} / \mathrm{m}$ (Fig. 2A) and shear stresses at the plate base are expected to be about $10^{5}$ to $10^{6} \mathrm{~N} / \mathrm{m}^{2}$. These are in good agreement with independent estimates of these forces [5,54], although it must be emphasized that they are only order-of-magnitude figures because of the simplicity of the calculation.

Comparisons of Chapple and Tullis' [4] and Forsyth and Uyeda's ([3], scaled to a ridge push of $2 X$ $10^{12} \mathrm{~N} / \mathrm{m}$, used here) estimates show that these authors require a slightly larger resistance to slab motions $\left(2-3 \times 10^{13} \mathrm{~N} / \mathrm{m}\right)$ to resist the greater slab pull, and an approximately equivalent drag at the plate bases. It is possible that a significant proportion of the resistance to slab motion is from its compositional buoyancy (section 2), thus the resistance to motion at trenches cannot simply be converted to a shear stress estimate.

Thus, it seems that our suggestion of a driving force that is dependent on the age of the slab does not make predictions that are contrary to the observations of plate motions. It should be noted, however, that taking account of this age dependence, and of the probable resistance to subduction due to compositional buoyancy and shearing resistance, leads us to the suggestion that the push from the ridges is an important factor in determining plate motions.

If a study taking account of the proposed changes in driving force as a function of age were thought worthwhile, and if it gave results similar to those in this section, it would then seem that the driving force from the ridges plays a greater part in plate motions than is usually supposed; the reduced slab pull would require a lower resistance to slab descent at the trenches and perhaps a relatively greater role for sublithospheric drag in resisting the motions.

If we have systematically underestimated the negative buoyancy of the younger slabs, these conclusions will not be reached. It appears from the discussion of this section that our assumptions produce no obvious shortfall in the global sum of the driving forces nor in the forces on the individual plates, and it is encouraging that a consistent scheme of driving forces can be erected on - albeit different - models of agedependent slab pull [52].

\section{Conclusions}

We have suggested a quantitative framework to explain the observations of differing tectonic styles in the regions behind subduction zones containing oceanic lithosphere of different ages. The driving forces in favour of the subduction of oceanic lithosphere - principally the negative buoyancy owing to its thermal contrast with the mantle - are strongly dependent on the age of the oceanic lithosphere. If the age of the lithosphere is too young its negative buoyancy and the push from the mid-ocean ridge may not be great enough to overcome the forces resisting subduction. The consumption of slab to the buoyant side of this transition may result in increased coupling between the overriding and subducting plates - through increase of shear stress at, or of width of, the plate boundary. This could produce compressive stresses of around $1 \mathrm{kbar}$ in the overriding plate.

Stresses of this order are sufficient to account for the observations of compressional tectonics behind zones where subduction of young lithosphere is occurring. The transition between tensional and compressional tectonics is predicted to occur when the age of lithosphere in the subduction zone drops below about 70 (40) Myr (Fig. 1) for the slabs with a descent velocity of $20(80) \mathrm{mm} / \mathrm{yr}$. Good agreement is found between this prediction and the observations of compressional and tensional regimes 
behind subduction zones containing slabs of different ages and descent velocities.

We expect compressive phases of cordilleran orogeny to arise from the crossing of this transition involving subduction of more buoyant lithosphere, this will result from a decrease in age and/or descent velocity of the slab.

If the age-dependent buoyancy of slabs is of importance it seems that, as far as present-day plate motions are concerned, the ridges must play an important role in driving the plates, and that the subduction of a ridge thus becomes doubly important in that it requires a large compressive force while removing a significant part of the total available driving force.

\section{Acknowledgements}

We are grateful to Dan McKenzie for helpful discussions and to Dan Karig and an anonymous reviewer for valuable criticisms. We thank Prof. N.J. Vlaar for encouragement and for arranging P.C.E.'s visit to Utrecht while this work was carried out.

\section{References}

1 W.M. Elsasser, Convection and stress-propagation in the upper mantle, Princeton Univ. Tech. Rep. 5 (1967).

2 D.P. McKenzie, Speculations on the consequences and causes of plate motion, Geophys. J.R. Astron. Soc. 18 (1969) 1.

3 D. Forsyth and S. Uyeda, On the relative importance of the driving forces of plate motion, Geophys. J.R. Astron. Soc. 43 (1975) 163.

4 W.M. Chapple and T.E. Tullis, Evaluation of the forces that drive the plates, J. Geophys. Res. 82 (1977) 1967.

5 F.M. Richter and D.P. McKenzie, Simple plate models of mantle convection, J. Geophys. 44 (1978) 441.

6 E.R. Oxburgh and E.M. Parmentier, Compositional and density stratification in oceanic lithosphere - causes and consequences, J. Geol. Soc. London 133 (1977) 343.

7 M.J. O'Hara, Is there an Icelandic mantle plume?, Nature 253 (1975) 708.

8 D.P. McKenzie, The initiation of trenches: a finite amplitude instability, in: Island Arcs, Deep Sea Trenches and Back-Arc Basins, M. Talwani and W.C. Pitman, eds., Am. Geophys. Union, Maurice Ewing Ser. 1 (1977) 57.

9 N.J. Vlaar and M.J.R. Wortel, Lithospheric aging, instability and subduction, Tectonophysics 32 (1976) 331.

10 M.J.R. Wortel and N.J. Vlaar, Age-dependent subduction of oceanic lithosphere beneath western South America, Phys. Earth Planet. Inter. 17 (1978) 201.
11 P. Molnar and T. Atwater, Interarc spreading and Cordilleran tectonics as alternates relating to the age of subducted oceanic lithosphere, Earth Planet. Sci. Lett. 41 (1978) 330 .

12 P. Molnar, D. Freedman and J.S.F. Shih, Lengths of intermediate and deep seismic zones and temperatures in downgoing slabs of lithosphere, Geophys. J.R. Astron. Soc. 56 (1979) 41.

13 B. Parsons and D.P. McKenzie, Mantle convection and the thermal structure of the plates, J. Geophys. Res. 83 (1978) 4485.

14 B. Parsons and J.G. Sclater, An analy sis of the variation of ocean floor bathymetry and heat flow with age, $\mathrm{J}$. Geophys. Res. 82 (1977) 803.

15 B.L. Isacks and P. Molnar, Distribution of stresses in the descending lithosphere from a global survey of focal mechanism solutions of mantle earthquakes, Rev. Geophys. Space Phys. 9 (1971) 103.

16 G. Schubert and D.L. Turcotte, Phase changes and mantle convection, J. Geophys. Res. 76 (1971) 1424.

17 D.L. Turcotte and G. Schubert, Structure of the olivinespinel boundary in the descending lithosphere, J. Geophys. Res. 76 (1971) 7980.

18 D.E. Karig, Origin and development of marginal basins in the western Pacific, J. Geophys. Res. 76 (1971) 2542.

19 A.G. Smith, Paper presented at Thrust and Nappe Conference, Imperial College, London, April 1979.

20 J.G. Sclater, Heat flow and elevation of the marginal basins of the western Pacific, J. Geophys. Res. 77 (1972) 5705.

21 J.G. Sclater, D.E. Karig, L.A. Lawver and K.E. Louden, Heat flow, depth and crustal thickness of the marginal basins of the South Philippine Sea, J. Geophys. Res. 81 (1976) 309.

22 T. Watanabe, M.G. Langseth and R.N. Anderson, Heat flow in back-arc basins of the western Pacific, in: Island Arcs, Deep Sea Trenches and Back-Arc Basins, M. Talwani and W.C. Pitman, eds., Am. Geophys. Union, Maurice Ewing Ser. 1 (1977) 137.

23 W.C. Pitman III, R.L. Larson and E.M. Herron, The Age of the Ocean Basins and Magnetic Lineations of the Ocean (charts) (Geological Socicty of America, Boulder, Colo., 1974).

24 Scientific Staff, Deep Sea Drilling Project, Leg 30, Southwest Pacific structures, Geotimes 18, No. 9 (1973) 19.

25 Scientific Staff, Deep Sea Drilling Project, Leg 31, Western Pacific floor, Geotimes 18, No. 10 (1973) 22.

26 J.B. Minster, T.H. Jordan, P. Molnar and E. Haines, Numerical modelling of instantaneous plate tectonics, Geophys. J.R. Astron. Soc. 36 (1974) 541.

27 T. Seno, The instantaneous rotation vector of the Philippine Sea plate relative to the Eurasian plate, Tectonophysics 42 (1977) 209.

28 M. Katsumata and L.R. Sykes, Seismicity and tectonics of the western Pacific: Izu-Mariana-Caroline and RyukyuTaiwan regions, J. Geophys. Res. 74 (1969) 5923.

29 M. Barazangi and B.L. Isacks, Spatial distribution of earth- 
quakes and subduction of the Nazca plate beneath South America, Geology 4 (1976) 686.

30 K.H. Jacobs, K. Nakamura and J.N. Davies, Trenchvolcano gap along the Alaska-Aleutian arc: facts, and speculations on the role of terrigenous sediments for subduction, in: Island Arcs, Deep Sea Trenches and BackArc Basins, M. Talwani and W.C. Pitman, eds., Am. Geophys. Union, Maurice Ewing Ser. 1 (1977) 243.

31 R.P. Riddihough, A model for recent plate interactions off Canada's west coast, Can. J. Earth Sci. 14 (1977) 384.

32 T.H. Jordan, The present-day motions of the Caribbean plate, J. Geophys. Res. 80 (1975) 4433.

33 B.P. Luyendijk, W.B. Bryan and P.A. Jezek, Shallow structure of the New Hebrides Arc, Geol. Soc. Am. Bull. 85 (1.974) 1287.

34 l:. Megard and H. Philip, Plio-Quaternary tectono-magmatic zonation and plate tectonics in the Central Andes, Earth Planet. Sci. Lett. 33 (1976) 231.

35 W. Stauder, Subduction of the Nazca plate under Peru as evidenced by focal mechanisms and by seismicity, J. Geophys. Res. 80 (1975) 1053.

36 J.F. Tomblin, Circum-Pacific and Caribbean orogens: the Lesser Antilles, in: Mesozoic-Cenozoic Orogenic Belts, A.M. Spencer, ed. (Scottish Academic Press, Edinburgh, 1974) $663-670$.

37 E.H. Lathram and 14 others, Circum-Pacific and Caribbean orogens: Alaska, in: Mesozoic-Cenozoic Orogenic Belts, A.M. Spencer, ed. (Scottish Academic Press, Edinburgh, 1974) 563-589.

38 D.E. Karig, Evolution of arc systems in the western Pacific, Annu. Rev. Earth Planet. Sci. 2 (1974) 51.

39 B.M. Herman, R.N. Anderson and M. Truchan, Extensional tectonics in the Okinawa Trough, FOS Trans. Am. Geophys. Union 58 (1977) 504 (abstract).

40 D.C. Noble, Some observations of the Cenozoic volcanotectonic evolution of the Great Basin, western United States, Earth Planet. Sci. Lett. 17 (1972) 142.

41 R.L. Christiansen and P.W. Lipman, Cenozoic volcanism and plate-tectonic evolution of the western United States, II, Late Cenozoic, Philos. Trans. R. Soc. London, Ser. A, 271 (1972) 249.

42 T. Atwater, Implications of plate tectonics for the Cenozoic tectonic evolution of western North America, Geol. Soc. Am. Bull. 81 (1970) 3513.
43 C.H. Scholz, M. Barazangi and M.L. Sbar, Late Cenozoic evolution of the Great Basin, western United States, as an ensialic interarc basin, Geol. Soc. Am. Bull. 82 (1971) 2979.

44 T.W.C. Hilde, S. Uyeda and L. Kroenke, Evolution of the western Pacific and its margin, Tectonophysics 38 (1977) 145.

45 P. Tapponier and P. Molnar, Slip-line field theory and large-scale continental tectonics, Nature 264 (1976) 319.

46 A. B. Watts, J.K. Weissel and R.L. Larson, Seafloor spreading in marginal basins of the western Pacific, Tectonophysics 37 (1977) 167.

47 T.J. Fitch and C.H. Scholz, Mechanism of underthrusting in southwest Japan: a model of convergent plate interactions, J. Geophys. Res. 76 (1971) 7260.

48 J. Dubois, J. Launay, J. Recy and J. Marshall, New Hebrides trench: subduction rate from associated lithospheric bulge, Can. J. Farth Sci. 14 (1977) 250.

49 J.A. Katili, Alpine-Himalayan orogens: Sumatra, in: Mesozoic-Cenozoic Orogenic Belts, A.M. Spencer, ed. (Scottish Academic Press, Edinburgh, 1974) 317-331.

50 H. Williams, A.R. McBirney and G. Dengo, Geologic reconnaissance of southeastern Guatemala, Univ. Calif. Publ. Geol. Sci. 50 (1964).

51 Z. de Cserna, Orogenesis in time and space in Mexico, Geol. Rundsch. 50 (1960) 595.

52 J.F. Harper, Asthenosphere flow and plate motion, Geophys. J.R. Astron. Soc. 55 (1979) 87.

53 D.E. Karig, J.G. Caldwell and E.M. Parmentier, Effects of accretion on the geometry of the descending lithosphere. J. Geophys. Res. 81 (1976) 6281.

54 D.P. McKenzie and G.T. Jarvis, Conversion of heat into mechanical work by convection (submitted to J. Geophys. Res.).

55 J.T. Wilson and K. Burke, Two types of mountain building, Nature 239 (1972) 448.

56 S. Uyeda and H. Kanamori, Back-arc opening and mode of subduction, J. Geophys. Res. 84 (1979) 1049.

57 W. Llsasser, Sea floor spreading as convection, J. Geophys. Res. 76 (1971) 1101.

58 J. Kelleher, J. Savino, H. Rowlett and W. McCann, Why and where great thrust earthquakes occur along island arcs, J. Geophys. Res. 79 (1979) 4889. 